\title{
The Kinetic Effect of Some Wine Components on the Enzymatic Hydrolysis of $\beta$-glucan
}

\author{
A. Zinnai, F. Venturi, M.F. Quartacci, A. Andreotti and G. Andrich*
}

Dipartimento di Chimica e Biotecnologie Agrarie, University of Pisa, Via del Borghetto 80, 56124 Pisa, Italy

Submitted for publication: July 2009

Accepted for publication: February 2010

Key words: $\beta$-glucan, ethanol, enzymatic hydrolysis, glucose, phenols

\begin{abstract}
Enzymatic preparations containing $\beta$-glucanases are utilised extensively in winemaking to facilitate the filtration of musts and wines coming from grapes affected by Botrytis cinerea, and to induce the release of mannoproteins and oligosaccharides from the cell walls of yeasts. The aim of the present work was to investigate the possible inhibitory effect of some wine components, and in particular of ethanol, on $\beta$-glucanase activities. For this purpose, the kinetic activity of a commercial enzymatic preparation containing $\beta$-glucanases was tested utilising both model solutions (buffer solution having a pH value similar to a must/wine with or without $13 \% \mathrm{v} / \mathrm{v}$ of ethanol added) and a red wine. When ethanol was added to the model solution, both the kinetic constant $k$ and glucose production suffered a decrease of about $50 \%$ compared to the values detected in the absence of ethanol. A further loss of activity (about $\mathbf{8 7 \%}$ ) was found using red wine as reaction medium, suggesting, as already reported in the literature, that phenols could add their inhibitory effect to that of ethanol. The results obtained provide useful suggestions that can be adopted during winemaking. To promote the hydrolysis of the possible excess of $\beta$-glucan coming from grapes affected by Botritis cinerea, it would be more convenient to add $\beta$-glucanases before a significant amount of ethanol accumulates in the must/wine, while it is not possible to avoid the negative impact of ethanol or other possible inhibitors (phenols) to promote yeast degradation in wine left on lees.
\end{abstract}

\section{INTRODUCTION}

Enzymatic preparations are utilised extensively in winemaking, both during the pre-fermentative as well as the post-fermentative phases (Palomero et al., 2007), and some of these, presenting $\beta$-glucanasic activity, are able to promote the hydrolysis of $\beta$-D-glucans. These polysaccharides are widely diffused in nature and can be found in some algae, fungi and yeasts, and are also present in crops such as barley and oats. The $\beta$-D-glucans constitute a main chain formed by $\beta$-D-glucose units joined together by $\beta-1,3$ (yeasts and fungi such as Saccharomyces cerevisiae, S. bayanus and Botrytis cinerea) or $\beta-1,4$ (cereals) glucosidic bonds, and by a variable number of lateral chains with different lengths that are linked to the main chain by $\beta-1,6$ or $\beta-1,2$ bonds. In this way it is possible to obtain a large number of different $\beta$-glucans with different chemical-physical properties and, in particular, different water solubility values (Dubourdieu et al., 1981; Villettaz et al., 1984).

The presence of a reduced amount of this protecting colloid ( 5 to $15 \mathrm{mg} / \mathrm{L}$ ) dissolved in must/wine and coming from grapes affected by B. cinerea (Dubourdieu et al., 1981; Villettaz et al., 1984) prevents the natural sedimentation of cloud particles and induces filter stoppages (Humbert-Goffard et al., 2004). However, at the end of the alcoholic fermentation yeasts undergo a process of degradation that involves the lysis of the cell walls, followed by the release into the wine of their main constituents and, among these, of mannoproteins and oligomeric fragments of $\beta$-glucans (Morata et al., 2003; Comuzzo et al., 2005). In order to induce a significant extraction of these compounds, the finished wines must be maintained in contact with the dregs of fermentation for long times (six to 12 months) and stirred frequently (batônnage). To reduce these long periods, the related high costs and the risk of a loss of quality due to the possible formation of undesired flavours (reduced volatile substances formed in low oxidative conditions), commercial preparations rich in $\beta$-glucanases can be utilised.

Most enzymes present in commercial preparations are extracted from fungi, particularly from Aspergillus spp., and can be divided into two large classes on the basis of the function of their main enzymatic activities (Parodi, 2002). The first class includes enzymes that are able to promote the hydrolysis of esters (pectinmethyl-esterases and pectin-esterases), while in the other class one finds those enzymes that are able to reduce the molecular weight of polymeric compounds (polymethylgalacturonase, polygalacturonase, pectintranseliminase, pecticacidtranseliminase and $\beta$-glucanases). $\beta$-glucanases include the $\beta$ - $(1,6)$ form, which promotes the hydrolysis of $\beta$ - $(1,6)-O$-glicosidic bonds connecting lateral branches with the main polymeric chain of $\beta$-glucans, as well as exo- $\beta-(1,3)$ and endo- $\beta$ - $(1,3)$-glucanases which promote the lysis of terminal and internal $\beta-(1,3)$-bonds respectively.

In spite of the considerable utilisation of these commercial preparations, it is still not possible to obtain a clear picture of the inhibitory effect due to the different components of wine, and in particular whether ethanol is able to play any kinetic role in $\beta$-glucanase activities. In fact, according to what has already been reported in literature, ethanol does not inhibit enzymatic activity, making $\beta$-glucan less soluble, and the highest inhibition of $\beta$-glucanase activities was observed during the growth phase of the yeasts at the start of alcoholic fermentation (Villettaz et al., 1984). Assuming the truth of this statement, all that HumbertGoffard et al. (2004) could relate to the $\mathrm{pH}$ change from 5.0 to 
3.4 was the loss of activity observed when comparing the results obtained in acetate buffer $(\mathrm{pH}=5.0)$ with those found utilising a model wine solution $(12 \% \mathrm{EtOH} v / \mathrm{v} ; 3 \mathrm{~g} / \mathrm{L}$ of $\mathrm{L}(+)$-tartaric acid; $\mathrm{pH}$ adjusted to 3.4 ) in which both $\mathrm{pH}$ and ethanol content were changed simultaneously.

Very many components of wine may act as enzymatic inhibitors and, of these, phenols do not appear to have a secondary role, as tannin substances can irreversibly inactivate enzyme proteins (Villettaz et al., 1984; Humbert-Goffard et al., 2004). To evaluate the inhibitory effect induced by ethanol or other wine compounds separately, the kinetic activity of a commercial enzymatic preparation (Vinoflow $G$ - Laffort Oenologie) was tested by utilising different reaction media. In particular, a model solution consisting of $\beta$-glucan extracted from yeasts (Sigma) and dissolved in a citrate buffer ( $\mathrm{pH}$ 3.3) to obtain a $\mathrm{pH}$ value similar to a must/wine, and the same solution to which was added $13 \%(\mathrm{v} / \mathrm{v})$ of ethanol to ensure an alcohol content close to that of a wine, were used and the experimental results were compared with those found directly using a red wine as reaction medium.

Because of the large number and chemical complexity of the compounds (oligosaccharides characterised by different molecular structure and weight) that could potentially be obtained by the lysis of $\beta$-glucan polysaccharides (Dubourdieu et al., 1981; HumbertGoffard et al., 2004), the hydrolytic activity shown by the tested enzymatic preparation was evaluated following the accumulation in the reaction medium of the end product, namely D-glucose.

\section{MATERIALS AND METHODS}

The granular preparation Vinoflow $G$ (Laffort Oenologie) contains pectinases and $\beta$-glucanases isolated from microbial strains of Aspergillus niger and Trichoderma harzianum. This enzymatic additive is classified "food grade" because mycotoxins are absent, the concentration of heavy metals is lower than 30 $\mu \mathrm{g} / \mathrm{L}$, the concentrations of $\mathrm{Pb}$ and $\mathrm{As}$ are lower than 5 and 3 $\mu \mathrm{g} / \mathrm{L}$ respectively, and no antibiotic activity is present. Vinoflow $G$ appears to be particularly active in promoting the degradation of pectic substances and the hydrolysis of $\beta$-glucans, thus it can also be employed usefully during wine stabilisation to increase the wine's filterability, thereby reducing the possible need to add other clarifiers. Moreover, the utilisation of this enzymatic preparation is recommended at concentrations of $\mathrm{SO}_{2}$ dissolved in wine that are lower than $500 \mathrm{mg} / \mathrm{L}$ and at temperatures higher than $12^{\circ} \mathrm{C}$ (Parodi, 2002).

The $\beta$-glucan utilised as enzymatic substrate was isolated from alcoholic yeasts ( $S$. cerevisiae), and presents a high degree of polymerisation and a relevant number of lateral branches (Sigma, product no. G5011).

In a $200 \mathrm{~mL}$ glass vessel, $10 \mathrm{~mL}$ of a Vinoflow $G$ solution containing $50 \mathrm{mg}$ of enzymatic preparation dissolved in $1 \mathrm{~L}$ of citrate buffer were added to $90 \mathrm{~mL}$ of a $\beta$-glucan solution $(500 \mathrm{mg}$ of $\beta$-glucan in $1 \mathrm{~L}$ of citrate buffer). The buffer was prepared by adding $448 \mathrm{~mL}$ of a solution containing $105.05 \mathrm{~g}$ of citric acid in $1 \mathrm{~L}$ of $1 \mathrm{~N} \mathrm{NaOH}$ to $552 \mathrm{~mL}$ of $0.1 \mathrm{~N} \mathrm{HCl}$. The model solution, which had a $\mathrm{pH}$ (3.3) value similar to a must/wine, contained $5 \mathrm{~g} /$ $\mathrm{hL}$ of Vinoflow $G$ and $45 \mathrm{~g} / \mathrm{hL}$ of $\beta$-glucan. The same procedure was followed to prepare the solution having an ethanol content similar to wine. In this case, instead of de-ionised water, a hydro- alcoholic solution containing $13 \%(\mathrm{v} / \mathrm{v})$ of ethanol was used for the preparation of the citrate buffer.

To prevent any microbial contamination that could affect D-glucose accumulation over time, the glass vessel was previously sterilised by a suitable heat treatment, while the sterility of the two solutions used (Vinoflow $G$ and $\beta$-glucan) was ensured by filtration $(0.22 \mu \mathrm{m})$. Moreover, to avoid any undesired oxidation from occurring, the experimental runs were carried out while maintaining the glass vessel under an inert atmosphere of $\mathrm{N}_{2}$ previously sterilised by filtration, while a constant temperature $\left(35^{\circ} \mathrm{C}\right)$ was ensured by a thermostatic bath. The addition of the Vinoflow $G$ solution $(10 \mathrm{~mL})$ to $\beta$-glucan $(90 \mathrm{~mL})$ represented the initial time of the kinetic run $(\mathrm{t}=0)$. A standard experimental run lasted more than a week.

The red wine utilised as the reaction medium of the enzymatic commercial preparation under investigation was produced by way of a traditional winemaking process at a controlled temperature $\left(27^{\circ} \mathrm{C}\right)$, using Merlot grapes harvested near Pisa (Tuscany, Italy). Alcoholic fermentation was carried out for about six days, the homogenisation of the must/wine was carried out by pumping over, and no $\mathrm{SO}_{2}$ or sulphites were added. The Official Methods of Analysis were utilised to evaluate the main chemical-physical characteristics of this wine (Horwitz, 2000).

The amount of D-glucose accumulated in the reaction media was evaluated by commercial enzymatic kits (Diffchamb, Megazyme). The identification of the best values to be assigned to the functional parameters of the mathematical equation used to relate the evolution of the experimental data over time was carried out by a commercial statistical program (Buzzi Ferraris \& Manca, 1996). This program identifies, in a space of $\mathrm{j}$-dimensions (where $\mathrm{j}$ represents the number of equation parameters), the minimum value of the $\mathrm{F}$ function, which is obtained from the sum of the squares of differences occurring between calculated $(\mathrm{R} *$ calc.,i) and experimental $(\mathrm{R} *$ exper.,i) values:

$$
\mathrm{F}=\sum_{\mathrm{i}=1}^{\mathrm{N}}\left(\mathrm{R}_{\text {calc, }, \mathrm{i}}^{*}-\mathrm{R}_{\text {exper, } \mathrm{i}}^{*}\right)^{2}
$$

where $\mathrm{i}=\mathrm{i}$-calculated/experimental value; $\mathrm{N}=$ total number of experimental values.

\section{RESULTS AND DISCUSSION}

The enzymatic activities shown by $\beta$-glucanases as a function of the composition of the reaction medium used were determined following the accumulation of D-glucose over time (Fig. 1). To allow an easier and immediate comparison between different experimental runs, a kinetic equation was introduced that describes the evolution of $\mathrm{D}$-glucose in the reaction medium by a reduced number of functional parameters.

The D-glucose accumulation can be described well by a curve that tends to an asymptotic maximum value (Fig. 2). In this way, the rate of D-glucose production $\left(\mathrm{d}[\mathrm{Glu}]_{\mathrm{t}-\mathrm{t}} / \mathrm{dt}\right)$ was hypothesised to be proportional to the difference between the maximum concentration of D-glucose, which could potentially be obtained when the extraction time tends to infinite $\left([\mathrm{Glu}]_{\mathrm{t}-\infty}\right.$, the asymptotic maximum value), and that ([Glu $\left.]_{t-t}\right)$ actually present in the reaction medium at a generic time $(\mathrm{t}=\mathrm{t})$ : 


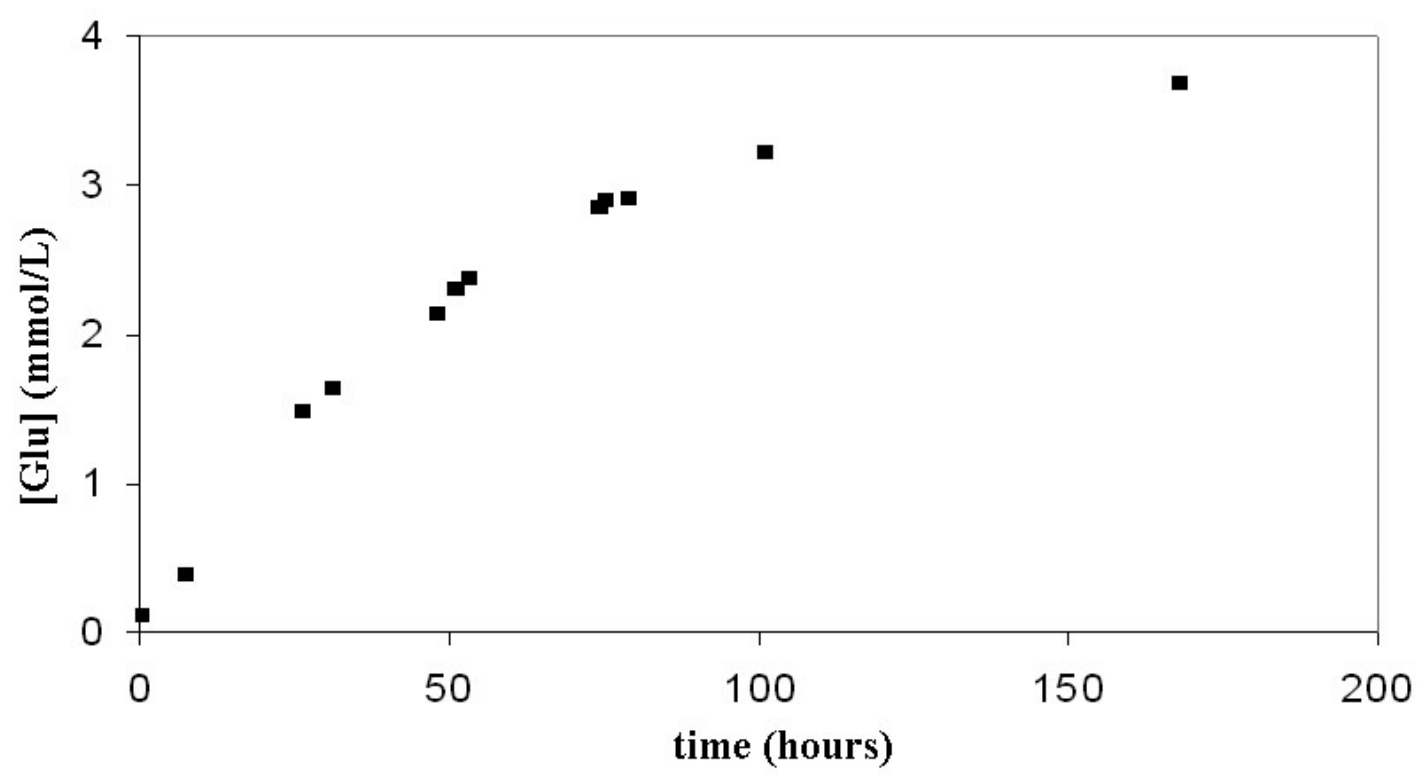

FIGURE 1

Evolution of experimental points related to D-glucose produced by the hydrolysis of $\beta$-glucan, representative of a generic enzymatic run.

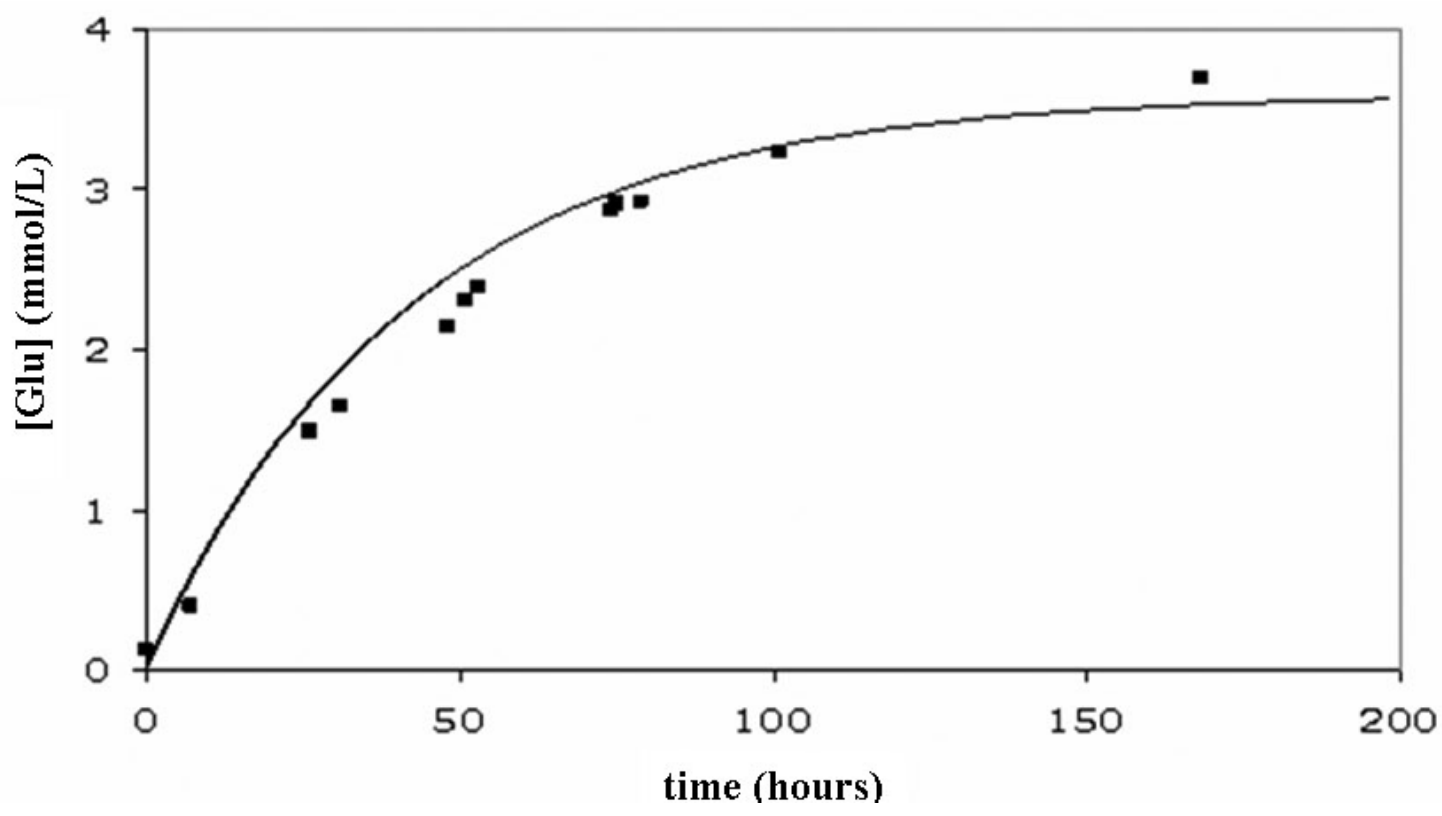

FIGURE 2

Evolution of experimental and calculated points by the kinetic equation introduced related to D-glucose produced by hydrolysis of $\beta$-glucan.

$\mathrm{d}[\mathrm{Glu}]_{\mathrm{t}=\mathrm{t}} / \mathrm{dt}=\mathrm{k}\left([\mathrm{Glu}]_{\mathrm{t}=\infty}-[\mathrm{Glu}]_{\mathrm{t}=\mathrm{t}}\right)$

where $\mathrm{k}$ represents the kinetic constant related to D-glucose accumulation. This differential equation can be integrated usefully to obtain a kinetic relation that describes the evolution over time of the D-glucose concentration (Fig. 2) in the reaction medium:

$[\mathrm{Glu}]_{\mathrm{t}=\mathrm{t}}=[\mathrm{Glu}]_{\mathrm{t}=\infty}\left(1-\mathrm{e}^{-\mathrm{kt}}\right)$

The two functional parameters $\mathrm{k}$ and $[\mathrm{Glu}]_{\mathrm{t}=\infty}$ were assumed to be valid measures of the kinetic effect induced on $\beta$-glucanase activities by the different reaction conditions. While the $\mathrm{k}$ constant appears to be strongly related to the initial rate:

$\mathrm{d}[\mathrm{Glu}]_{\mathrm{t}=\mathrm{t}} / \mathrm{dt}=\mathrm{d}\left([\mathrm{Glu}]_{\mathrm{t}=\infty}\left(1-\mathrm{e}^{-\mathrm{kt}}\right)\right) / \mathrm{dt}=[\mathrm{Glu}]_{\mathrm{t}=\infty} \mathrm{k} \mathrm{e}^{-\mathrm{kt}}$

$\lim _{\mathrm{t} \rightarrow 0}\left(\mathrm{~d}[\mathrm{Glu}]_{\mathrm{t}=\mathrm{t}} / \mathrm{dt}\right)=\lim _{\mathrm{t} \rightarrow 0}\left([\mathrm{Glu}]_{\mathrm{t}=\infty} \mathrm{k} \mathrm{e}^{-\mathrm{kt}}\right)=[\mathrm{Glu}]_{\mathrm{t}=\infty} \mathrm{k}$

the ratio between the maximum concentration that could potentially be reached by D-glucose in a particular experimental condition (the value assumed by the asymptotic maximum $[\mathrm{Glu}]_{\mathrm{t}-\infty}$ ) and the maximum concentration $(4.3 \mathrm{mmol} / \mathrm{L})$ that could potentially be 


\section{TABLE 1}

Mean values assumed by the two functional parameters, $\mathrm{k}$ and $[\mathrm{Glu}]_{t=\infty}$, at $35^{\circ} \mathrm{C} \pm$ confidence intervals (c.i., $\left.\mathrm{p}=0.05\right)$ following the addition of $\beta$-D-glucan and/or enzymatic preparation to different reaction solutions (citrate buffer with a $\mathrm{pH}$ value similar to a must/wine, with or without $13 \% \mathrm{v} / \mathrm{v}$ ethanol, and to a red wine).

\begin{tabular}{|c|c|c|c|c|c|c|}
\hline Run & Reaction medium & $\begin{array}{c}\text { Enzymatic } \\
\text { preparation }\end{array}$ & $\beta$-D-glucan & $\begin{array}{c}\mathbf{k} \cdot 10^{-3} \\
\left(\mathbf{h}^{-1}\right)\end{array}$ & $\underset{(\mathbf{m m o l} / \mathbf{L})}{[\mathrm{Glu}]_{\mathrm{t}=\infty}}$ & $r^{2}$ \\
\hline 1 & Citrate buffer & Yes & Yes & $37.02 \pm 0.04$ & $3.9 \pm 0.3$ & 0.98 \\
\hline 2 & Citrate buffer + ethanol & Yes & Yes & $24.04 \pm 0.05$ & $2.2 \pm 0.5$ & 0.97 \\
\hline 3 & Wine & No & No & not detectable & not detectable & - \\
\hline 4 & Wine & No & Yes & not detectable & not detectable & - \\
\hline 5 & Wine & Yes & No & $3.89 \pm 0.27$ & $1.9 \pm 0.2$ & 0.96 \\
\hline 6 & Wine & Yes & Yes & $3.16 \pm 0.23$ & $1.6 \pm 0.4$ & 0.98 \\
\hline
\end{tabular}

produced by the complete hydrolysis of all $\beta$-glucan added, would represent a valid measure of the yield of D-glucose that can be reached under those experimental conditions.

To identify the best values to be assigned to the functional parameters ( $\mathrm{k}$ and $[\mathrm{Glu}]_{\mathrm{t}=\infty}$ ) involved in kinetic equation (3), the statistical program Burenl was utilised (Buzzi Ferraris \& Manca, 1996). The high values assumed by the squares of the correlation coefficients calculated for the linearised form of the kinetic equation in the Taylor series (Table 1) give an indication of the suitability of the theoretical approach followed and of the reliability of the related kinetic equations obtained.

When the same experimental conditions were utilised (4.3 $\mathrm{mmol} / \mathrm{L}$ of glucan dissolved in a citrate buffer solution at $\mathrm{pH} 3.3$ and a temperature of $35^{\circ} \mathrm{C}$ ), statistically equivalent values for the two functional constants $\mathrm{k}$ and $[\mathrm{Glu}]_{\mathrm{t}=\infty}$ were obtained. Indeed, the sum of the related confidence intervals $\left(\sum{\mathrm{c} . \mathrm{i}_{\mathrm{k}}}_{\mathrm{k}}=(17+18) \cdot 10^{-3}=\right.$ $\left.35 \cdot 10^{-3} \mathrm{~h}^{-1} ; \Sigma{\mathrm{c} . \mathrm{i}_{[\text {Glu }] \mathrm{t}=\infty}}=(0.5+0.4)=0.9 \mathrm{mmol} / \mathrm{L}\right)$ appears to be greater than the differences occurring between the corresponding mean values calculated by Burenl $\left(\Delta_{\mathrm{k}}=(42-37) \cdot 10^{-3}=5 \cdot 10^{-3} \mathrm{~h}^{-1}\right.$; $\left.\Delta_{[\text {Glu }]=\infty}=(3.5-3.3)=0.2 \mathrm{mmol} / \mathrm{L}\right)$. Thus, all the data collected under the same experimental conditions were used to calculate the values assumed by the two functional parameters $\mathrm{k}$ and [Glu] $t=\infty$ (Table 1).

When ethanol was added to the aqueous buffer solution in order to ensure an alcoholic content similar to a wine (13\% $\mathrm{v} / \mathrm{v})$, no precipitate formation was observed and the reaction medium remained clear. As reported in the literature, to cause the precipitation of this colloid a value of about $30 \%$ of ethanol should be reached (Villettaz et al., 1984).

Under these conditions the values assumed by the two kinetic constants, $\mathrm{k}$ and $[\mathrm{Glu}]_{\mathrm{t}=\infty}$, suffered a remarkable decrease (about $35 \%$ ) compared to those detected in the absence of ethyl alcohol (Table 1). In contrast to what was reported in a previous paper, where both $\mathrm{pH}$ and ethanol content were changed simultaneously (Humbert-Goffard et al., 2004), in this case the loss of kinetic activities should be ascribed only to the addition of ethanol.

To evaluate the kinetic behaviour of the enzymatic preparation under realistic working conditions, its catalytic activity was also measured at $35^{\circ} \mathrm{C}$ using a red wine. The main analytical and chemical-physical characteristics of the wine are reported in Table 2. The $\mathrm{pH}$, total and volatile acidity values (Table 2)

\section{TABLE 2}

Chemical-physical characteristics of the red wine used as reaction solution and related confidence intervals (c.i., $p=0.05$ ).

\begin{tabular}{lc}
\hline Chemical physical characteristics & Mean \pm c.i. \\
\hline Reducing sugars $(\mathrm{g} / \mathrm{L})$ & $<2$ \\
Ethanol $(\%, \mathrm{v} / \mathrm{v})$ & $13.0 \pm 0.5$ \\
$\mathrm{pH}$ & $3.20 \pm 0.01$ \\
Total acidity (g/L tartaric acid) & $5.65 \pm 0.07$ \\
Volatile acidity (g/L acetic acid) & $0.43 \pm 0.01$ \\
Total phenols (g/L catechin) & $3.50 \pm 0.03$ \\
Total anthocyanins (g/L malvidine) & $0.85 \pm 0.02$ \\
Free anthocyanins (g/L malvidine) & $0.26 \pm 0.01$ \\
\hline
\end{tabular}

detected were standard, as were the values of the reducing sugars and ethanol, with the latter showing a concentration equal to that previously used in the model solution $(13 \% \mathrm{v} / \mathrm{v})$. Moreover, the wine showed significantly high concentrations of anthocyanins and total phenols (Table 2). Phenolic compounds are well known for their ability to form stable adducts with proteins, and in the case of enzymes a consequent loss may occur in their catalytic activities (Villettaz et al., 1984; Humbert-Goffard et al., 2004). This consideration might explain the significant loss of activity (about $85 \%$ ) when using the wine instead of the hydro-alcoholic solution as reaction medium (compare $\mathrm{k}$ values of runs 2 and 6 , Table 1). The involvement of phenols in explaining this further decrease in $\beta$-glucanase activities appears to be in accordance with the results reported by Humbert-Goffard et al. (2004).

A significant amount of glucan coming from the lysis of the cell walls of yeasts appeared to be dissolved in the wine, so that the mere addition of the enzymatic preparation induced the accumulation of a remarkable amount of D-glucose (run 5, Table 1). On the contrary, no hydrolysis of $\beta$-D-glucan occurred in the pure wine (run 3, Table 1) or when this polysaccharide was added to the wine in the absence of the enzymatic additive (run 4, Table 1). Moreover, no relevant differences occurred using the wine with the same amount of the enzymatic preparation in the presence or absence of $\beta$-D-glucan (compare run 5 and 6, Table 1). Thus, an increase in substrate 
concentration ( $\beta$-D-glucan) does not seem to be able to induce any significant increase in D-glucose production.

\section{CONCLUSIONS}

The inhibition of D-glucose production due to ethanol and other wine components was investigated utilising both model solutions and wine with or without ethanol and/or $\beta$-D-glucan. The results obtained provide useful suggestions to be taken into consideration during winemaking:

- while the inhibitory action due to ethanol ( $\sim-35 \%)$ can sometimes be avoided, that induced by other must/wine components and, in particular, by phenols $(\sim-85 \%)$ is always present and active;

- to promote the hydrolysis of the possible excess of $\beta$-glucan coming from the pressing of grapes affected by Botritis cinerea, it appears to be more convenient to utilise enzymatic preparations before a significant amount of ethanol deriving from alcoholic fermentation accumulates in the reaction medium;

- in any case, the inhibitory action of ethyl alcohol produced by fermentation cannot be avoided when the addition of exogenous glucanases is aimed at increasing the dissolution, in the finished wines, of compounds coming from the autolysis of yeasts (mannoproteins, oligosaccharides).

The negative effects induced by these inhibitors might be partially overcome by increasing the concentration of the enzymatic preparation.

\section{LITERATURE CITED}

Buzzi Ferraris, G. \& Manca, D., 1996. BURENL. Politecnico, Dipartimento di Ingegneria Chimica "G. Natta”, Milano.

Comuzzo, P., Battistutta, F. \& Tasso, A., 2005. Effet d'un lysat industriel de lévure sur l'évolution des vins rouges en bouteille. J. Int. Sci. Vigne Vin 39, 83-90.

Dubourdieu, D., Ribereau-Gayon, P. \& Fournet, B., 1981. Structure of exocellular B-D-glucan from Botrytis cinerea. Carbohydr. Res. 93, 294-299.

Horwitz, W. (ed), 2000 (17th ed). Official methods of analysis of AOAC International, vol. II. AOAC (Association of Official Analytical Chemists), Maryland.

Humbert-Goffard, A.H., Saucier, C., Moine-Ledoux, V., Canal-Llaubères, R.M., Dubourdieu, D. \& Glories, Y., 2004. An assay for glucanase activity in wine. Enz. Microb. Tech.. 34, 537-543.

Morata, A., Gomez-Cordovéz, M.C., Suberviola, J., Bartolomé, B., Colomo, B. \& Suarez, J.A., 2003. Adsorption of anthocyanins by yeast cell walls during the fermentation of red wines. J. Agr. Food Chem. 51, 4084-4088.

Palomero F., Morata, A., Benito, S., Gonzales, M.C. \& Suarez-Lepe, J.A., 2007. Conventional and enzyme-assisted autolysis during ageing over lees in red wines: influence on the release of polysaccharides from yeast cell walls and on wine nonnumeric anthocyanin content. Food Chem. 105, 838-846.

Parodi, G., 2002. L'affinamento dei vini con 1'ausilio di preparati enzimatici. Vignevini 5, 54-58.

Villettaz, J.C., Steiner, D. \& Trogus, H., 1984. The use of $\beta$-glucanase as an enzyme in wine clarification and filtration. Am. J. Enol. Vitic. 35, 253-256. 